\title{
The Optimization of Mix Proportions for Cement Paste Backfill Materials via Box-Behnken Experimental Method
}

\author{
Chaoqun Dai ${ }^{1,2}$ (1) Aixiang $\mathrm{Wu}^{1,2} \cdot$ Yan $\mathrm{Qi}^{1,2} \cdot$ Zhiqiang Chen ${ }^{1,2}$
}

Received: 8 January 2019/Accepted: 8 March 2019/Published online: 30 March 2019

(C) The Author(s) 2019

\begin{abstract}
Cemented paste backfill (CPB) technology has been applied quite popular around the world. Determining a reliable filling material mix proportions is an important aspect of mine backfilling. To produce effective $\mathrm{CPB}$ materials at copper mines technologically and economically, Box-Behnken design experimental program (four factors and three levels) was carried out to test the optimal mix proportions with unclassified tailings. Results of the test indicated that slump decreased first and then increased with the increase in the pumping agent content. However, the slump decreased with the mass concentration, cement content and tailing/rock ratio. And 28-day uniaxial compressive strength (UCS) was positively correlated with rock content and mass concentration. The sensitive degrees of each variable to the slump and UCS were determined, and the influence of law and mechanism of each factor on the response value was analyzed. Relationships of paste properties and influential factors can be demonstrated with regression analysis. Additionally, the optimal mix proportion for cement paste backfill was obtained with $76.75 \%$ mass concentration, 3.35 tailing/rock ratio, 0.1 cement/(tailing + rock) ratio and $1.24 \%$ pumping agent addition. The slump and UCS of the optimal mixture were $24.1 \mathrm{~cm}$ and $1.59 \mathrm{MPa}$, respectively. The experimental results showed a feasible way to produce the industry standard backfilling materials.
\end{abstract}

Chaoqun Dai

s20170079@xs.ustb.edu.cn

1 School of Civil and Resource Engineering, University of Science and Technology Beijing, Beijing 100083, China

2 Key Laboratory of the Ministry of Education of China for High-Efficient Mining and Safety of Metal Mines, Beijing 100083, China
Keywords Unclassified tailings - Cement paste backfill . Mix proportion - Box-Behnken design .

Experimental optimization

\section{Introduction}

In order to meet the needs of sustainable economic development, the development of mineral resources is growing. With the depletion of shallow surface resources and the growing demand for mineral resources in social development, deep well mining will be the future direction of mining [1,2]. Due to the characteristics of deep mining high stress, high ground pressure and high ground temperature, coupled with the sustainable development trend of building green mines and mining, the backfilling mining method has become the preferred method for deep mining. CPB technology is favored by mining enterprises because of its non-stratification, non-segregation and non-precipitation characteristics [3]. CPB not only reduces the consumption of cement, but also effectively supports the roof, reduces drainage and makes the tailings produced by the mine fully utilized $[4,5]$. This not only controls the cost of filling the goaf significantly, but also improves the environmental pollution problem and promotes the sustainable development of the mine [6].

Paste is normally produced by coarse particles, fine particles and binders with specific mix proportions, and transported to underground stopes through reticulated pipelines. Due to the large amount of waste rock on the surface of the mine, the addition of waste rock can increase the strength of the filling body. The amount of cement determines the cost of mine filling, and using a small cement/(tailing + rock) ratio as much as possible can save 
costs. When the pressure of the filling pipe of the mine is large, the pumping agent can be appropriately added to reduce the resistance of the pipe to protect the pipeline and the pump. Therefore, the mass concentration, tailing/rock ratio $(T / R)$, cement/(tailing + rock) ratio $[C /(T+R)]$ and pumping agent addition were selected as the research object. Generally, the targeted physical and chemical properties of CPB are apparently affected by many parameters such as mobility, yield stress and UCS. However, UCS is an important criterion for determining the filling effect of mine goaf and whether the filling body can support the surrounding rock well. The slump determines whether the pipeline can safely and stably transport the paste slurry to the gob. Therefore, mix proportions of different materials are critical to obtain high-quality CPB with required industrial parameters.

Response surface methodology is an analysis method that analyzes the influence of multiple factors on the target variable (response value) based on the experimental data [7]. It can use the multivariate nonlinear regression method to establish the mathematical model between the response value and each influencing factor, and then seek the optimal experimental conditions [8]. Box-Behnken is a response surface design method, especially for the study of factors ranging from 3 to 7 . Multivariate quadratic equations can be used to fit the functional relationship between multiple factors and response values, analyze the response value and the nonlinear relationship between the various factors [9]. The paper used this method based on a certain number of experiments; the effects of the mass concentration, tailing/rock ratio, cement/(tailing + rock) ratio, pumping agent addition and their interaction on the slump and UCS were comprehensively analyzed to obtain the optimal experimental conditions. Based on the experimental data, range analysis was introduced to understand the sensitive degrees of each variable to targeted properties, and regression analysis was used to quantitatively demonstrate the relationships between independent variables and dependent variables. The work showed that the combination of Box-Behnken design, range analysis and regression analysis was a feasible way to produce the satisfied cemented paste backfilling materials.

\section{Materials and Methods}

\section{Tailings}

The tailings were collected from the discharge points of the tailing pond of Beishtamu copper mine, northwest China. The density is $2.662 \mathrm{t} / \mathrm{m}^{3}$, the loose porosity of tailings is $55.3 \%$, and the dense porosity is $39.74 \%$. Main compositions of tailings include $57.11 \% \quad \mathrm{SiO}_{2}, 19.25 \% \quad \mathrm{Fe}_{2} \mathrm{O}_{3}$,
$11.43 \% \mathrm{CaO}, 2.86 \% \mathrm{MgO}, 4.28 \% \mathrm{Al}_{2} \mathrm{O}_{3}$ and $0.98 \% \mathrm{~S}$. The laser particle analyzer test showed that the ultrafine particle contents of $-5 \mu \mathrm{m},-10 \mu \mathrm{m}$ and $-20 \mu \mathrm{m}$ in the unclassified tailings are $12.3 \%, 20.5 \%, 29.8 \%$, and -200 mesh $(-74 \mu \mathrm{m})$ are $64.32 \%,-325$ mesh $(-45 \mu \mathrm{m})$ are $43.1 \% . d_{10}, d_{30}, d_{60}$ are $3.9 \mu \mathrm{m}, 21.3 \mu \mathrm{m}$ and $71.6 \mu \mathrm{m}$, respectively. The nonuniform coefficient $C_{\mathrm{U}}$ of the unclassified tailings is 18.36 , and the curvature coefficient $C_{\mathrm{C}}$ value is 1.62 . Figure 1 shows that granular distribution of tailings had a relatively wide range and a smooth continuous distribution.

\section{Rocks}

The rock samples were taken from the surface waste rock near the mine and were milled to $-10 \mathrm{~mm}$ for transport to the laboratory. The density is $2.667 \mathrm{t} / \mathrm{m}^{3}$, the loose bulk density of waste rock is $1.524 \mathrm{t} / \mathrm{m}^{3}$, the dense bulk density is $1.863 \mathrm{t} / \mathrm{m}^{3}$, and the porosity is $22.6 \%-31.6 \%$. The X-ray fluorescence test showed that the composition of rocks was similar to the tailings. The $C_{\mathrm{U}}$ and $C_{\mathrm{C}}$ values are 17.05 and 1.47, respectively. Combined with the granular distribution of rock as shown in Fig. 1, it could be seen that the rocks size distribution range was wide and the rock grade was better.

\section{Cements}

The 42.5R Portland cement was used. The cement has a specific surface area of $415 \mathrm{~m}^{2} / \mathrm{kg}$, density of $3.03 \mathrm{t} / \mathrm{m}^{3}$ and dense bulk density of $1.424 \mathrm{t} / \mathrm{m}^{3}$. The granular distribution is shown in Fig. 1.

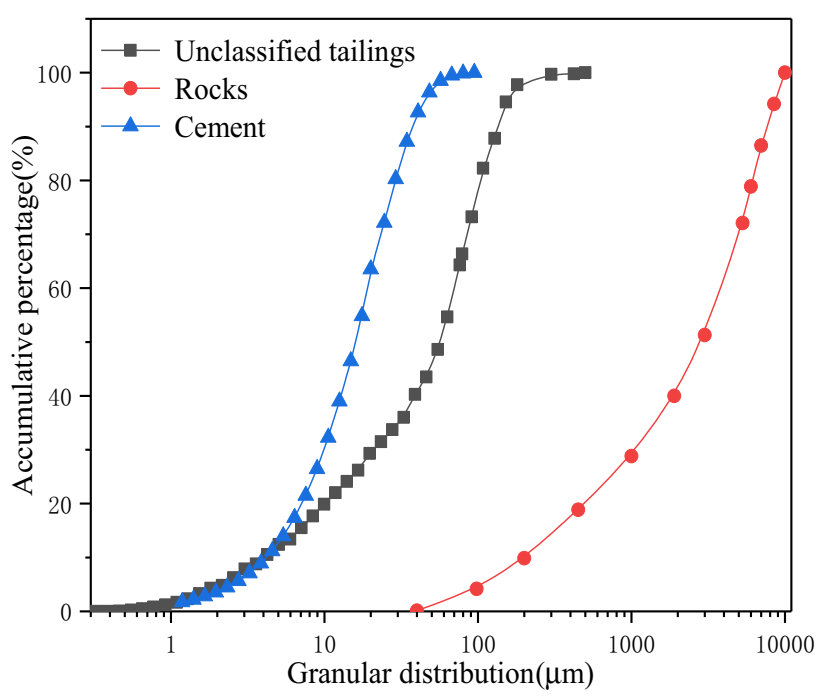

Fig. 1 Granular distribution of rocks, unclassified tailings and cement 


\section{Pumping Agent}

Through the paste additive test, the JK-5-type pumping agent was selected as an admixture for backfilling, polycarboxylic acid type and powder form. The amount of pumping agent added is the weight percent of the cement.

Table 1 Box-Behnken design experimental factors level and codes

\begin{tabular}{llll}
\hline Factor & Unit & Level $(-1)$ & Level $(+1)$ \\
\hline$x_{1}-$ mass concentration & wt $\%$ & 76 & 78 \\
$x_{2}-T / R$ & - & 2 & 4 \\
$x_{3}-C /(T+R)$ & - & 0.05 & 0.17 \\
$x_{4}-$ pumping agent addition & $\%$ & 1 & 2.5 \\
\hline
\end{tabular}

\section{Experimental Approach}

With the slump and UCS as the response indicators, the Box-Behnken design method was used to carry out the response surface experiment of mix proportion for CPB. The experiment was based on a four-factor and three-level combination design. The effects of mass concentration, $T /$ $R, C /(T+R)$ and pumping agent addition on the response value were investigated. The experimental factors and codes are shown in Table 1.

According to the four factors in Table 1, the BoxBehnken experimental scheme was obtained, a total of 29 experiments were performed. The program and results are shown in Table 2.

Table 2 Box-Behnken design experiment result

\begin{tabular}{|c|c|c|c|c|c|c|}
\hline Mixture & Mass concentration (wt\%) & $T / R$ & $C /(T+R)$ & Pumping agent addition (\%) & Slump $(\mathrm{cm})$ & UCS (MPa) \\
\hline 1 & 76 & 3 & 0.17 & 1.75 & 25.6 & 4.75 \\
\hline 2 & 76 & 4 & 0.11 & 1.75 & 27.6 & 1.41 \\
\hline 3 & 77 & 4 & 0.11 & 1 & 22.3 & 1.63 \\
\hline 4 & 76 & 3 & 0.05 & 1.75 & 26.8 & 0.29 \\
\hline 5 & 76 & 2 & 0.11 & 1.75 & 25.4 & 2.36 \\
\hline 6 & 77 & 3 & 0.11 & 1.75 & 23.8 & 2.01 \\
\hline 7 & 78 & 2 & 0.11 & 1.75 & 27.6 & 2.42 \\
\hline 8 & 77 & 3 & 0.17 & 2.5 & 24.9 & 5.08 \\
\hline 9 & 77 & 2 & 0.11 & 1 & 27.6 & 2.19 \\
\hline 10 & 77 & 3 & 0.05 & 1 & 25.2 & 0.35 \\
\hline 11 & 77 & 3 & 0.11 & 1.75 & 24.2 & 1.91 \\
\hline 12 & 78 & 3 & 0.11 & 2.5 & 22.6 & 2.33 \\
\hline 13 & 78 & 3 & 0.17 & 1.75 & 20.4 & 5.19 \\
\hline 14 & 77 & 3 & 0.17 & 1 & 24.9 & 4.51 \\
\hline 15 & 77 & 2 & 0.11 & 2.5 & 28.3 & 2.22 \\
\hline 16 & 77 & 4 & 0.05 & 1.75 & 21.9 & 0.76 \\
\hline 17 & 78 & 4 & 0.11 & 1.75 & 14.5 & 2.36 \\
\hline 18 & 77 & 4 & 0.17 & 1.75 & 20.7 & 4.78 \\
\hline 19 & 76 & 3 & 0.11 & 1 & 27.5 & 1.56 \\
\hline 20 & 78 & 3 & 0.05 & 1.75 & 21.7 & 0.98 \\
\hline 21 & 77 & 3 & 0.11 & 1.75 & 24 & 1.8 \\
\hline 22 & 77 & 2 & 0.05 & 1.75 & 27.2 & 0.54 \\
\hline 23 & 77 & 3 & 0.05 & 2.5 & 26.7 & 0.59 \\
\hline 24 & 77 & 3 & 0.11 & 1.75 & 24 & 2.23 \\
\hline 25 & 77 & 4 & 0.11 & 2.5 & 23 & 1.87 \\
\hline 26 & 77 & 3 & 0.11 & 1.75 & 24.1 & 1.99 \\
\hline 27 & 78 & 3 & 0.11 & 1 & 22 & 2.24 \\
\hline 28 & 77 & 2 & 0.17 & 1.75 & 26.1 & 5.23 \\
\hline 29 & 76 & 3 & 0.11 & 2.5 & 28.2 & 1.66 \\
\hline
\end{tabular}




\section{Paste Properties Test}

Slurry was prepared according to the designed mix proportions of tailings, rocks, cement, pumping agent and water. The slump was tested following the China national standard for test method of performance on ordinary fresh concrete (GB/T 50080-2002) [10]. The UCS tests were carried out according to the China national standard for test method of mechanical properties on ordinary concrete (GB/T 50081-2002) [11].

\section{Results and Discussion}

\section{Experimental Results of Paste Mix Proportions}

Table 2.

\section{Data Processing and Analysis}

\section{Regression Analysis}

Response surface experiment selected slump and UCS as response values; the multivariate quadratic correlation model between the mass concentration, $T / R, C /(T+R)$, the pumping agent addition amount and the response value was represented by Eq. (1):

$Y=\beta_{0}+\sum_{i=1}^{n} \beta_{i} x_{i}+\sum_{i=1}^{n} \beta_{i i} x_{i}^{2}+\sum_{i<j} \beta_{i j} x_{i} x_{j}$

where $Y$, response value; $\beta_{0}$, coefficient constant; $\beta_{i}$, the linear coefficient; $\beta_{i i}$, the coefficient of the quadratic equation; $\beta_{i j}$, the interaction coefficient; $n$, The number of experimental factors in this experiment was $4 ; x_{i}, x_{j}$, experimental factors codes values.

The data in Table 2 were processed by using the Design Expert 8.0.6 statistical analysis software for regression analysis. The slump $Y_{1}$ and UCS $Y_{2}$ can be predicted using the following relationships, as given by Eqs. (2)-(3).

$$
\begin{aligned}
Y_{1}= & -2435.1615+55.3442 x_{1}+291.9725 x_{2}+39.963 x_{3} \\
& -4.5174 x_{4}-3.825 x_{1} x_{2}-0.4167 x_{1} x_{3}-0.033 x_{1} x_{4} \\
& -0.4167 x_{2} x_{3}+7.4015 \times 10^{-16} x_{2} x_{4}-8.3333 x_{3} x_{4} \\
& -0.3017 x_{1}^{2}-0.0142 x_{2}^{2}-7.4074 x_{3}^{2}+2.4193 x_{4}^{2} \\
Y_{2}= & 389.6807-9.8428 x_{1}-17.6656 x_{2}+75.7097 x_{3} \\
& +0.6254 x_{4}+0.2225 x_{1} x_{2}-1.0417 x_{1} x_{3}-3.3333 \\
& \times 10^{-3} x_{1} x_{4}-2.7917 x_{2} x_{3}+0.07 x_{2} x_{4}+1.8333 x_{3} x_{4} \\
& +0.0623 x_{1}^{2}+0.0898 x_{2}^{2}+208.2639 x_{3}^{2}-0.1827 x_{4}^{2}
\end{aligned}
$$

Variance and Significance Analysis

Using the Design Expert software to create the variance results of the influencing factors interaction items as shown in Table 3.

Both regression equations reached a very significant level $(P<0.01)$. The lack of fit of Eq. (2) was $0.5936>0.05$, which was not significant, indicating that the equation was consistent with the experimental data and the stability was high. Model correlation coefficient $R^{2}=0.9989$, and correction coefficient $R_{\text {adj }}^{2}=0.9977$. The lack of fit of Eq. (3) was $0.7381>0.05$, which was not significant, $R^{2}=0.9958, R_{\mathrm{adj}}^{2}=0.991$. It was indicated that the predicted value of the slump and UCS of the BoxBehnken design experiment had a good fitting degree to the actual value obtained by the experiment. The equation had high authenticity and high confidence. Therefore, the equation can be used to analyze and predict the slump value and UCS in the mix proportion of CPB.

\section{Analysis of the Significance of Single-Factor Influence}

From Table 3, the influence of single factor on slump and UCS was significant. Combining with the influence of single factor as shown in Figs. 2 and 3, it could be seen that the influence of four single factors on the response value was also different. The sensitivity of influential factors to slurry slump was: $T / R>$ mass concentration $>$ pumping agent addition $>C /(T+R)$; the sensitivity to UCS was: $C /(T+R)>$ mass concentration $>T / R>$ pumping agent addition.

\section{Analysis of the Significance of Factor Interaction}

For the fitting results of the response surface, the contour shape and the three-dimensional surface can reflect the strength of the interaction between the factors. Some researches have shown that if the color changes faster in the $3 \mathrm{D}$ surface region, the steeper the surface, the more sensitive the response value is to the change in the two factors [12]. Some analysts believe that the contour is elliptical, indicating that the interaction between the two influencing factors is obvious; the contour is circular, and the interaction between the two influencing factors is not significant [13].

Analysis of the Effect of the Interaction of Experimental Factors on the Slump Value According to the variance analysis of the Design Expert statistical analysis software, it was known that the interaction term between the experimental factors had a significant effect on the slump value $x_{1} x_{2}(P<0.0001)$ and $x_{3} x_{4}(P=0.0001)$; the following two items were analyzed. 
Table 3 Box-Behnken design regression model analysis of variance

\begin{tabular}{|c|c|c|c|c|c|c|}
\hline Response & Source & Sum of squares & $d f$ & Mean square & $F$ value & $P$ value \\
\hline \multirow{15}{*}{ Slump } & Model & 252.42 & 14 & 18.03 & 879.01 & $<0.0001$ \\
\hline & $x_{1}$ & 86.94 & 1 & 86.94 & 4238.55 & $<0.0001$ \\
\hline & $x_{2}$ & 86.40 & 1 & 86.40 & 4212.35 & $<0.0001$ \\
\hline & $x_{3}$ & 3.97 & 1 & 3.97 & 193.42 & $<0.0001$ \\
\hline & $x_{4}$ & 1.47 & 1 & 1.47 & 71.67 & $<0.0001$ \\
\hline & $x_{1} x_{2}$ & 58.5225 & 1 & 58.5225 & 2853.099 & $<0.0001$ \\
\hline & $x_{1} x_{3}$ & 0.0025 & 1 & 0.0025 & 0.12188 & 0.7322 \\
\hline & $x_{1} x_{4}$ & 0.0025 & 1 & 0.0025 & 0.12188 & 0.7322 \\
\hline & $x_{2} x_{3}$ & 0.0025 & 1 & 0.0025 & 0.12188 & 0.7322 \\
\hline & $x_{2} x_{4}$ & $2.84 \mathrm{E}-14$ & 1 & $2.84 \mathrm{E}-14$ & $1.39 \mathrm{E}-12$ & 1.0000 \\
\hline & $x_{3} x_{4}$ & 0.5625 & 1 & 0.5625 & 27.4231 & 0.0001 \\
\hline & Residual & 0.29 & 14 & 0.021 & - & - \\
\hline & Lack of fit & 0.20 & 10 & 0.020 & 0.91 & 0.5936 \\
\hline & Pure error & 0.088 & 4 & 0.022 & - & - \\
\hline & Cor. total & 252.71 & 28 & - & - & - \\
\hline \multirow[t]{15}{*}{ UCS } & Model & 62.42 & 14 & 4.46 & 237.49 & $<0.0001$ \\
\hline & $x_{1}$ & 1.02 & 1 & 1.02 & 54.06 & $<0.0001$ \\
\hline & $x_{2}$ & 0.39 & 1 & 0.39 & 20.52 & 0.0005 \\
\hline & $x_{3}$ & 56.46 & 1 & 56.46 & 3007.41 & $<0.0001$ \\
\hline & $x_{4}$ & 0.13 & 1 & 0.13 & 7.16 & 0.0181 \\
\hline & $x_{1} x_{2}$ & 0.198025 & 1 & 0.198025 & 10.5474 & 0.0058 \\
\hline & $x_{1} x_{3}$ & 0.015625 & 1 & 0.015625 & 0.832234 & 0.3771 \\
\hline & $x_{1} x_{4}$ & $2.5 \mathrm{E}-05$ & 1 & $2.5 \mathrm{E}-05$ & 0.001332 & 0.9714 \\
\hline & $x_{2} x_{3}$ & 0.112225 & 1 & 0.112225 & 5.977439 & 0.0283 \\
\hline & $x_{2} x_{4}$ & 0.011025 & 1 & 0.011025 & 0.587224 & 0.4562 \\
\hline & $x_{3} x_{4}$ & 0.027225 & 1 & 0.027225 & 1.450085 & 0.2485 \\
\hline & Residual & 0.26 & 14 & 0.019 & - & - \\
\hline & Lack of fit & 0.16 & 10 & 0.016 & 0.65 & 0.7381 \\
\hline & Pure error & 0.1 & 4 & 0.025 & - & - \\
\hline & Cor. total & 62.69 & 28 & - & - & - \\
\hline
\end{tabular}

1. Analysis of the interaction effect of factor $x_{1} x_{2}$

The fixed $C /(T+R)$ was 0.11 , and the pumping agent addition amount was $1.75 \%$. From Fig. $4 \mathrm{a}$, in the experimental level range, the overall slump decreased with the increase in the mass concentration; when the $T / R$ was less than 3 , the amount of rock added was large, the $T / R$ was the dominant factor, and the effect of mass concentration change in the slump was not prominent. At this time, the specific surface area of the mixture was small, in comparison with absorbing less moisture; the increase in free water content caused lubrication which reduced the yield stress and apparent viscosity of the slurry, so the resistance was reduced during flow, the fluidity was improved, which caused the slump not to change significantly with concentration. When the $T / R$ was greater than 3 , the effect of slump reduction was most pronounced. This was because when the amount of rock added was reduced, the influence of concentration on slump was dominant. As the concentration of paste increased, the content of particles in the paste increased, the collision and the chance of mutual adsorption between fine particles were greater, the producing flocculated structure became more, the resistance of the slurry became larger, and the cohesiveness of the paste was increased, resulting in weaker flowability of the paste. Figure $4 \mathrm{~b}$ shows that the $T / R$ was higher than the contour line density along the moving direction of the mass concentration, indicating that the $T / R$ had a more significant effect on the slump than the mass concentration.

\section{Analysis of the interaction effect of factor $x_{3} x_{4}$}

The fixed mass concentration was $77 \%$, and the $T / R$ was 3. As shown in Fig. 5a, the slump value decreased slightly with the increase in the $C /(T+R)$, and the slump value decreased first and then increased with the increase in the 


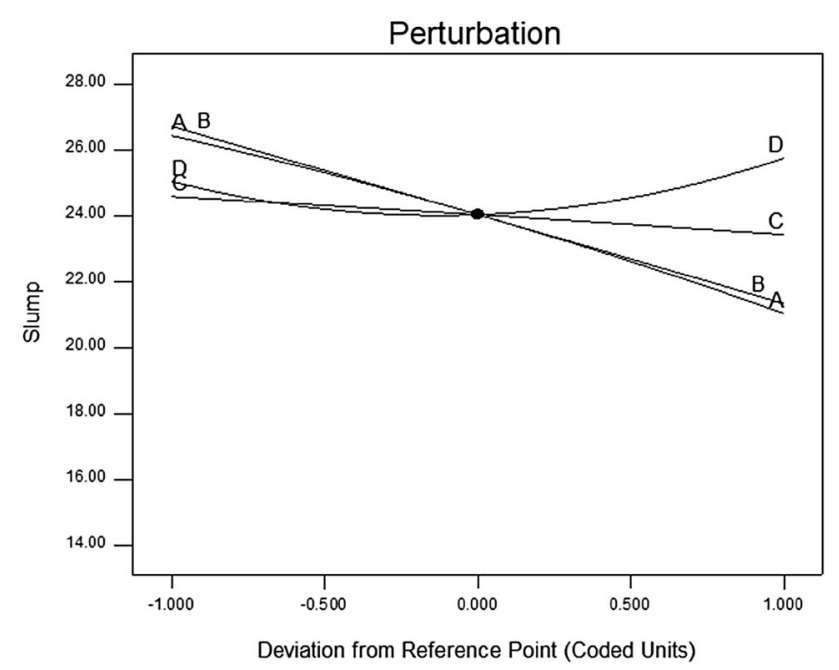

Fig. 2 Single-factor influence on slump

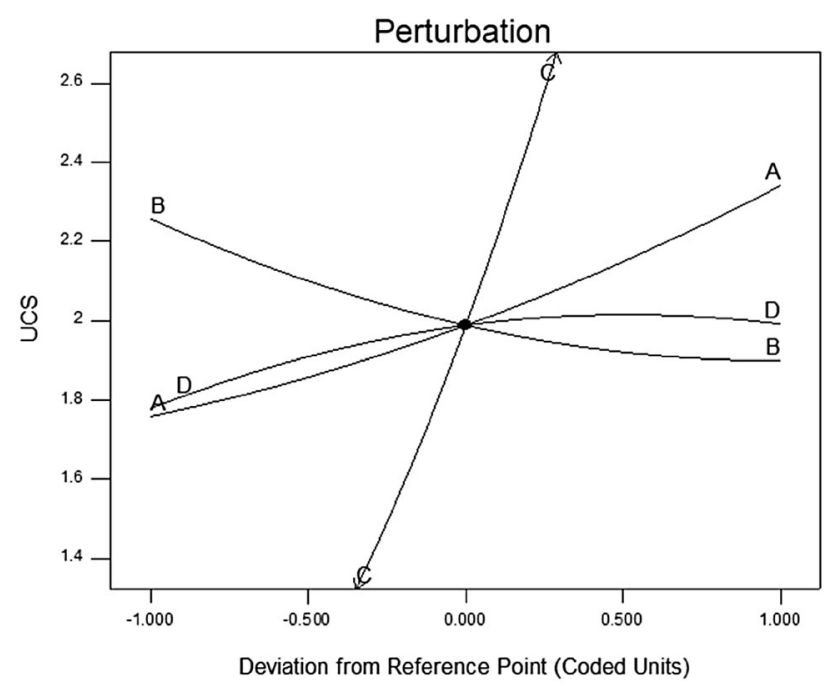

Fig. 3 Single-factor influence on UCS

pumping agent content. The influence of the pumping agent content on the slump was more significant than the $\mathrm{Cl}$ $(T+R)$. Before adding the pumping agent, the particle size of the floc in the paste slurry was larger; large pores and depressions were formed between the flocs which were honeycomb structures; when the content of the pumping agent was less than $1.75 \%$, a part of the large-sized flocs was broken, the small-sized flocs produced by the crushing filled the pores and depressions of the large flocs, so the porosity ratio was reduced. As the pumping agent content increased to $1.75 \%$, the internal pores were filled with the large number of broken flocs; the viscosity thereof was increased, resulting in a decrease in fluidity and reduction in slump. Pumping agent content continued to increase to $2.5 \%$, and the pumping agent destroyed the flocs and released the water wrapped in the flocs sequentially, which increased the free water and acted as lubrication; the volume of the floc was reduced simultaneously, thereby improving the flow properties of the paste slurry.

On the other hand, the cement particles are small and have a large specific surface area, which could absorb more water than the aggregate. As the cement content increased, the fine particle mass fraction increased, the contact and friction between the fine aggregates increased, the ability to plastically deform of the slurry was reduced, and the plastic viscosity was increased. So, the macroscopic performance of the slump was reduced, and the rheology was deteriorated.

Analysis of the Effect of Interaction of Experimental Factors on UCS The interaction term between the experimental factors had a significant significance on the UCS value $(P<0.01) . x_{1} x_{2}(P=0.0058)$, this item was analyzed below (Fig. 6).

\section{(1) Effect of mass concentration on UCS}

The fixed $C /(T+R)$ was 0.11 , and the pumping agent addition amount was $1.75 \%$. It was known from the response surface diagram that the UCS of the paste test piece increased as the mass concentration increased. This was because the average particle size of the cement is much smaller than the average particle size of the tailings, and the low concentration of the slurry would cause the segregation of the cement during the solidification process. In the cement mortar, when the particle diameter is less than $15 \mu \mathrm{m}$, a stable ion double layer was formed around the fine particles. The inside and outside of the electric double layer had the same amount of electricity and the opposite charge. As the two small particles were close to each other, the repulsive force of the same electric charge was greater than the attractive force; the particles were separated after the collision, and large particle mass cannot be formed to accelerate the sedimentation and they were in a suspended state, the sedimentation speed was slow. As the water in the CPB penetrated and overflowed, the small particles remained on the surface of the CPB. Small particles larger than $15 \mu \mathrm{m}$, although not forming a micelle, were not uniform during the settling process as well. Because according to the Stokes formula [14], the sedimentation velocity at the time of free sedimentation was proportional to the square of the particle diameter, as shown in formula (4).

$V_{0}=54.5 \frac{\rho_{\mathrm{s}}-\rho}{\mu} d^{2}$,

where $\rho_{\mathrm{s}}$, solid density; $\rho$, the density of water; $d$, particle diameter; $\mu$, the dynamic viscosity coefficient of water.

The general mass concentration of the filling slurry was 70-80\%. The particles were not freely settled, but interference settlement, which would slow down the difference of sedimentation, was caused by different particle sizes. 


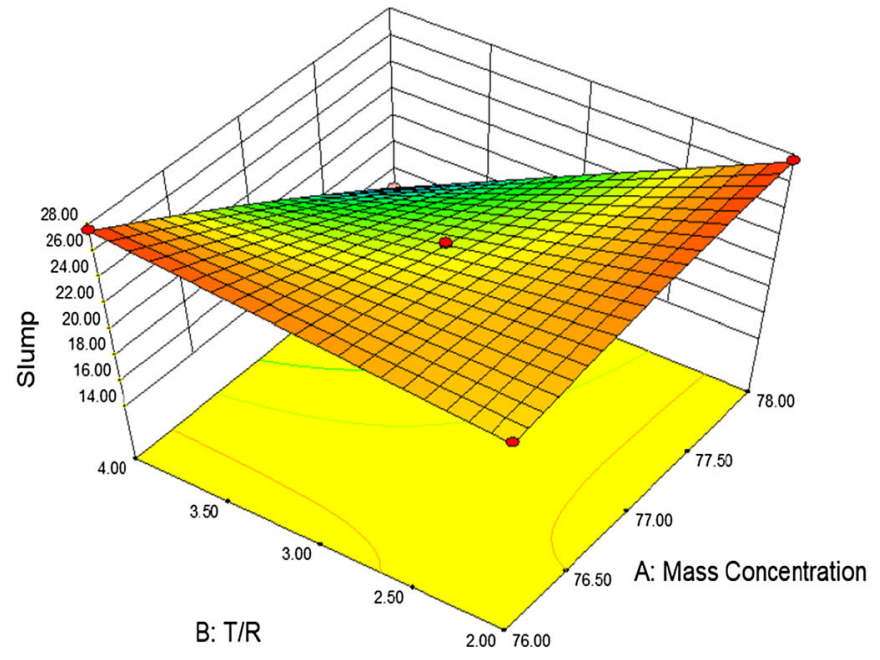

(a) Response surface map

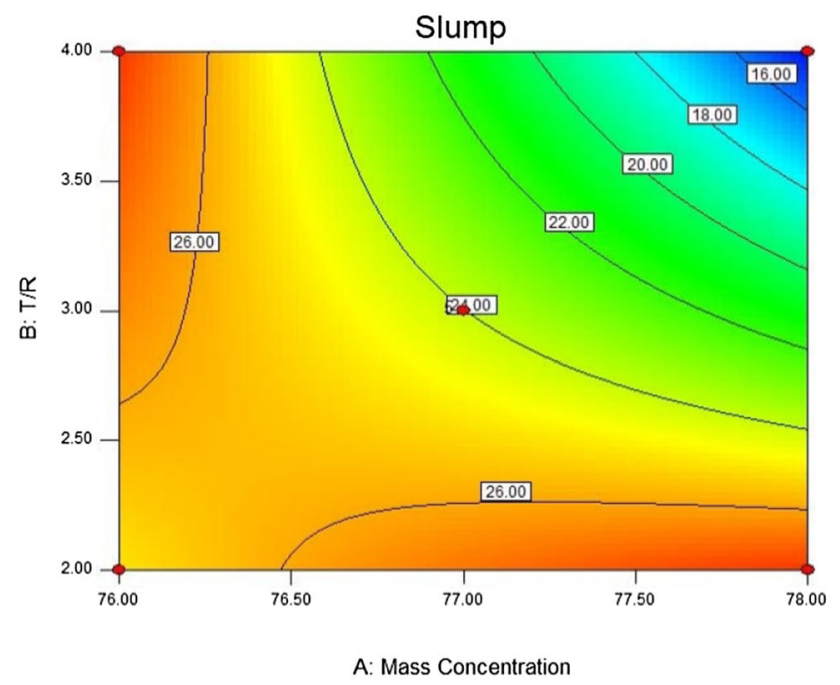

(b) Contour map

Fig. 4 Response surface and contour map of the interaction between the mass concentration and $T / R$ on slump

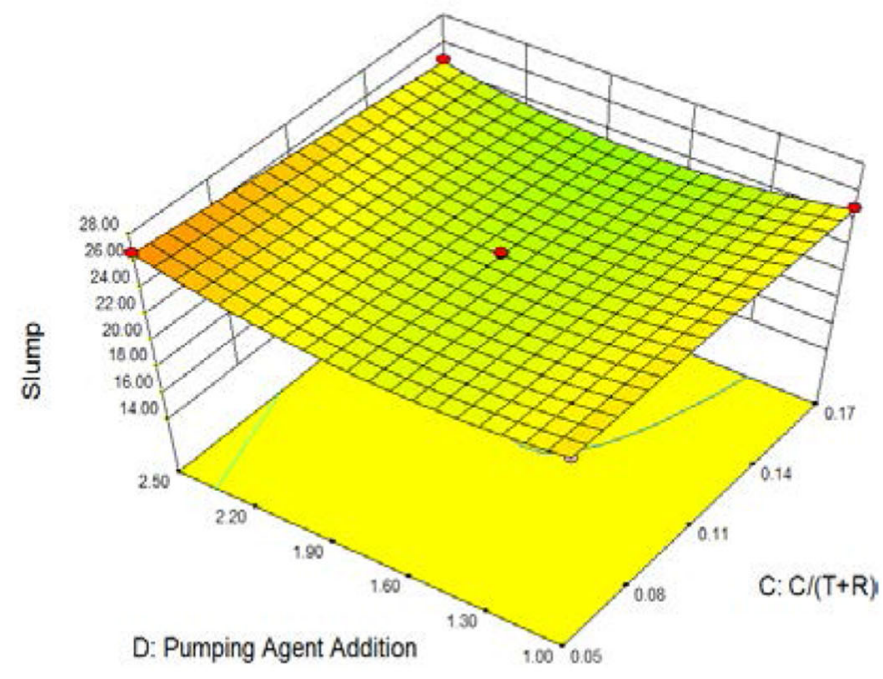

(a) Response surface map

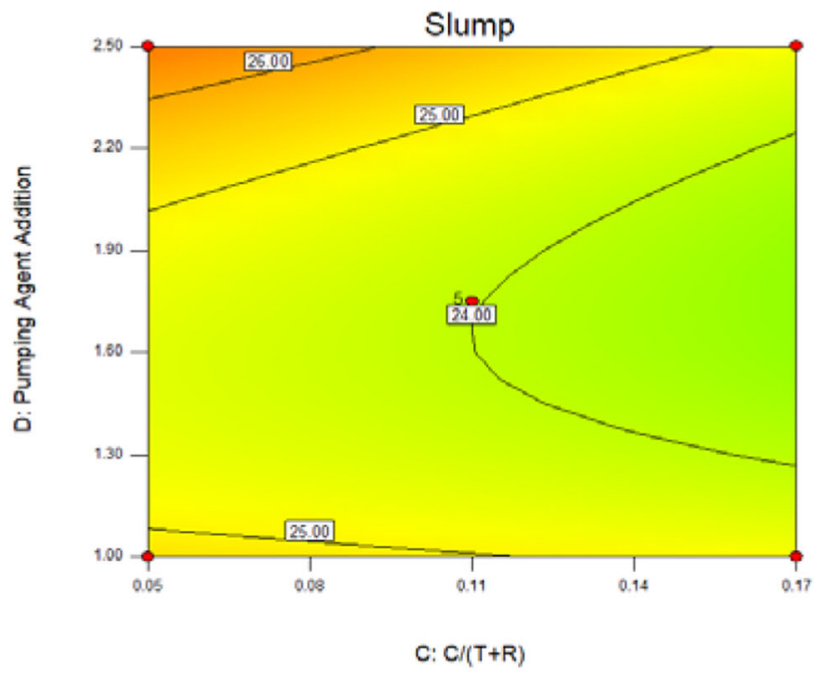

(b) Contour map

Fig. 5 Response surface and contour map of the interaction between the pumping agent addition and $C /(T+R)$ on slump

However, the general trend did not change, basically it was still the large particles with some of the small particles that sank below, above were the smaller particles of particle size.

For the above two reasons, the uppermost layer on the surface of the CPB was a fine particle of $5 \mu \mathrm{m}$ to $15 \mu \mathrm{m}$ which formed a micelle, contained a large amount of molecular water film, the particle size gradually increased downward, the large particle size in the lower layer was more, and the small particle size was few. After backfilling, a precipitate layer distributed according to particles size was formed in the CPB. The particles of +200 mesh in cement did not exceed 5\% (Fig. 1), and the particles of $-45 \mu \mathrm{m}$ in the unclassified tailings of Beishtamu have reached $43.1 \%$. So, a layer of mud with higher cement content remained on the surface of the CPB. Therefore, the higher the mass concentration, the higher the UCS of the CPB.

\section{(2) Effect of $T / R$ on UCS}

The UCS of the paste test block increased with the increase in the amount of rock added, but the actual UCS value did not increase much. Under the appropriate grading conditions, the larger particle size aggregate could obtain higher UCS and the best compacting effect also could be obtained, thereby improving the mechanical strength. According to the viewpoint of concrete science, in the 


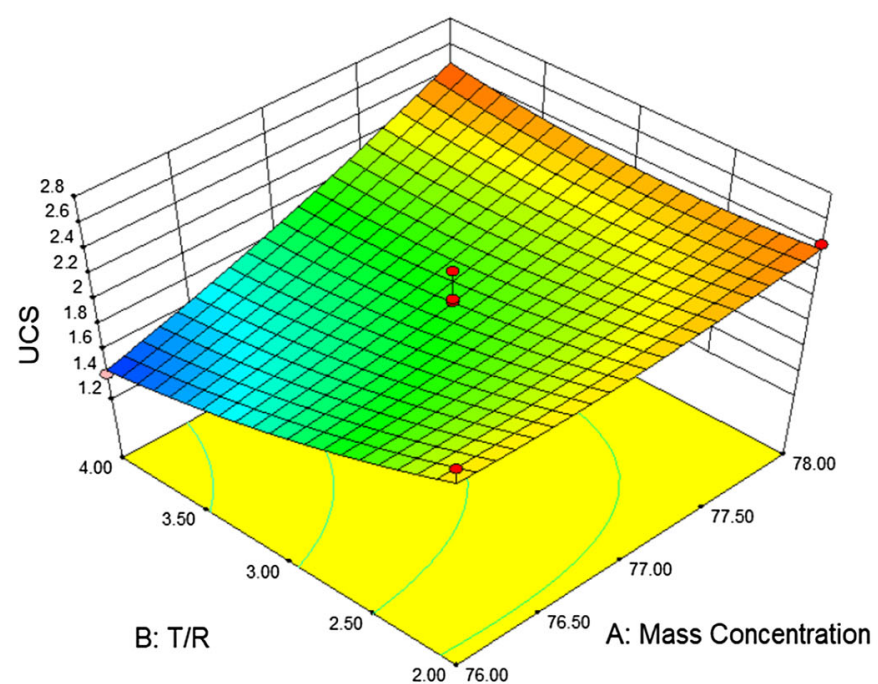

(a) Response surface map

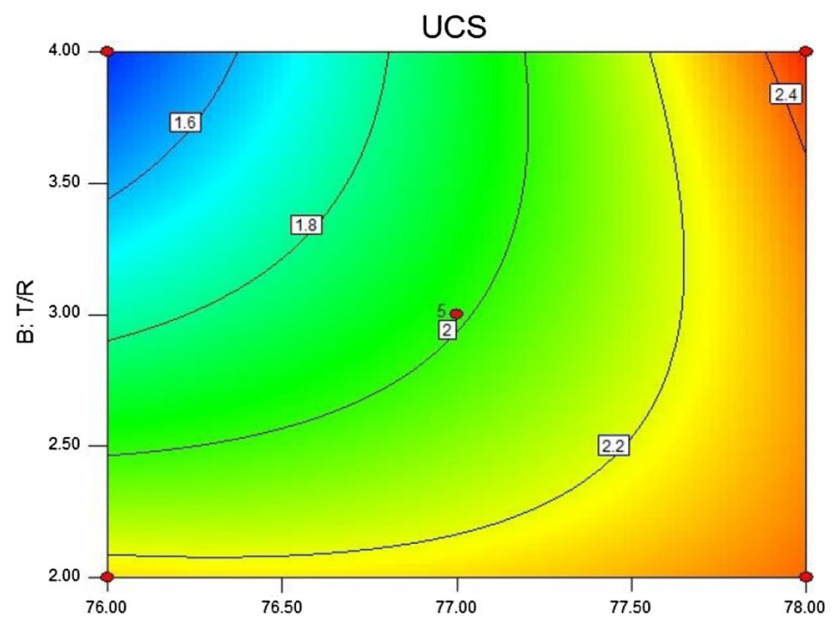

A: Mass Concentration

(b) Contour map

Fig. 6 Response surface and contour map of the interaction between the mass concentration and $T / R$ on UCS

combined structure of the cement slurry and the aggregate, the cement slurry is a dispersion medium and the aggregate is a dispersed phase. The aggregate constitutes the skeleton of the $\mathrm{CPB}$, which affects the mechanical strength of the CPB through denseness effect, frame effect, interface effect and mixing effect.

In the experiment, the $T / R$ was $2-4$, the rock content in the aggregate was only $20-33 \%$, and the frame effect cannot be formed. Only the denseness effect and the interface effect affect the strength of the paste. The denseness effect means that the coarse particles replace the small particles inside the same volume, thereby reducing the porosity and increasing the density of the aggregate; the interface effect means that the coarse particles replace the small particles inside the same volume, thereby reducing the specific surface area of the aggregate, so that the same amount of cement wraps a larger area. The addition of the Beishtamu copper ore rock had little effect on the compactness of the aggregate, as shown in Fig. 7.

From Fig. 7, when the unclassified tailings were mixed with the rock, the compactness of the aggregate was obviously improved only when the rock content reached $40 \%$ or more. In the experiment, in all the mixing ratios, the rock content was only $20 \%$ to $33 \%$, although the compactness rose faster, the actual value was not increased much, and the skeleton dense structure was not formed; therefore, the influence on the UCS was small.

\section{Optimization of Paste Mix Proportions}

Using the numerical function of optimization in Design Expert software, the slump degree satisfied $20-25 \mathrm{~cm}$ and

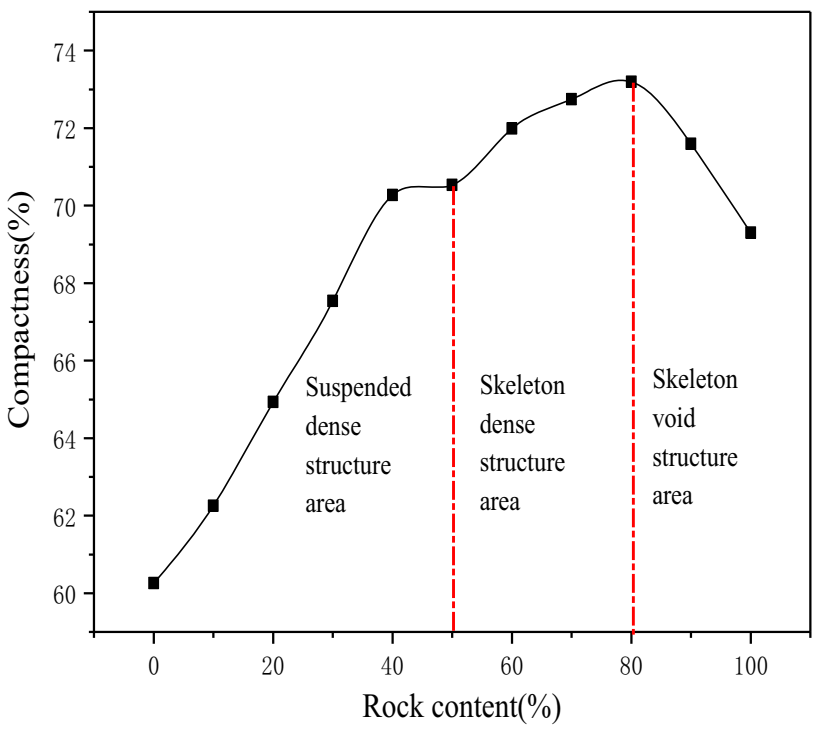

Fig. 7 Relationship between rock content and compactness

the UCS satisfied 1-2 MPa within the range of influencing factors. The optimal mix proportion for CPB was obtained with $76.75 \%$ mass concentration, $3.35 \mathrm{~T} / R, 0.1 \mathrm{C} /$ $(T+R)$ and $1.24 \%$ pumping agent addition. The slump and UCS of the mixture were $24.5 \mathrm{~cm}$ and $1.53 \mathrm{MPa}$, respectively.

The three sets of verification experiments were repeated in parallel under optimized conditions, and the average values of the slump and UCS were $24.1 \mathrm{~cm}$ and $1.59 \mathrm{MPa}$, respectively. The results show that the experimental values of the Box-Behnken design optimization experiment were basically consistent with the predicted values, indicating that the prediction model was effective. 
Finally, the optimized mix proportions were applied to the Beishtamu copper mine and achieved a good filling effect, and met the needs of mine production. Box-Behnken design method further realizes the efficient mining of mines and ensures the safety of mining operations and can provide reference for the mining of other similar mines.

\section{Conclusions}

1. Experimental factors consist of mass concentration, cement/(tailing + rock) ratio, tailing/rock ratio and pumping agent addition. A Box-Behnken design experiment (four factors and three levels) is carried out. Results of the test indicate that slump decreases first and then increases with the increases in the pumping agent content. However, the slump decreases with the mass concentration, cement content and $T /$ $R$. UCS is positively correlated with rock content and mass concentration. Furthermore, the range analysis of Box-Behnken design experiments shows that the sensitivity of influential factors to slurry slump is $T /$ $R>$ mass concentration $>$ pumping agent addition $>C /(T+R)$; the sensitivity to UCS is $C /(T+$ $R)>$ mass concentration $>T / R>$ pumping agent addition. The relationships of CPB properties (slump and UCS) and influential factors can be quantitatively demonstrated with equations derived from regression analysis.

2. The causes and mechanisms of the influence of four factors on slump and UCS are analyzed. Firstly, the reasons for the influence of various factors on the slump are explained from the perspective of floc structure, collision friction between particles and free water content. Then, the grain size distribution causes a stable ionic electric double layer to form around the fine particles; the interaction between them and the difference in the flocculation settling velocity form a sedimentary layer distributed according to the particles size, large particles together with some small particles sink below, above are more small particle sizes, which explains the effect of mass concentration on UCS. Finally, from the relationship between the amount of rock and compactness, the experimental data of the Beishtamu copper mine filling tailings ratio do not form a skeleton dense structure, the actual value of UCS increases little.

3. The optimal mix proportion for cement paste backfill with unclassified tailings is obtained with $76.75 \%$ mass concentration, 3.35 tailing/rock ratio, 0.1 cement/ (tailing + rock) and $1.24 \%$ pumping agent addition. The three sets of verification experiments were repeated in parallel under optimized conditions; the average values of the slump and UCS of the mixture are $24.1 \mathrm{~cm}$ and $1.59 \mathrm{MPa}$, respectively.

Acknowledgements The authors are thankful to the State Key Laboratory, High-efficient Mining and Safety of Metal Mines, Ministry of Education.

Open Access This article is distributed under the terms of the Creative Commons Attribution 4.0 International License ( http://creativecommons.org/licenses/by/4.0/), which permits unrestricted use, distribution, and reproduction in any medium, provided you give appropriate credit to the original author(s) and the source, provide a link to the Creative Commons license, and indicate if changes were made.

Funding This research was funded by the National Natural Science Foundation of China, Grant Number (51574013).

\section{References}

1. H.Z. Jiao, H.J. Wang, A.X. Wu, X.W. Ji, Q.W. Yan, Rule and mechanism of flocculation sedimentation of unclassified tailings. J Univ Sci Technol Beijing 32(6), 702-707 (2010)

2. Y.X. Ke, X.M. Wang, Q.L. Zhang, Flocculating sedimentation characteristic of pre-magnetized crude tailings slurry. Chin J Nonferrous Metals 27(2), 392-398 (2017)

3. J. Henriquez, P. Simms, Dynamic imaging and modelling of multilayer deposition of gold paste tailings. Miner. Eng. 22(2), 128 (2009)

4. N. Sivakugan, R.M. Rankine, K.J. Rankine, Geotechnical considerations in mine backfilling in Australia. J. Clean. Prod. 14(12-13), 1168 (2006)

5. Z.H. Guo, H.Q. Zhou, L.F. Wu, Numerical simulation for roof and surface subsidence process caused by paste filling. J Min Saf Eng 25(2), 172 (2008)

6. L. Liu, Research on Proportion Optimization and Flow Characteristic of Backfill Paste in Mine Sites. Dissertation, Central South University, Changsha (2013)

7. Y.X. Zhang, X. Wang, T. Hou, Efficient microwave-assisted production of biofuel ethyl levulinate from corn stover in ethanol medium. J Energy Chem 27(03), 890-897 (2018)

8. S. Kumar, R. Venugopal, Performance analysis of jig for coal cleaning using $3 \mathrm{D}$ response surface methodology. Int J Min Sci Technol 27(02), 333-337 (2017)

9. X.Y. Qiu, J.Y. Chen, X.Z. Shi, Deformation prediction and analysis of underground mining during stacking of dry gangue in open-pit based on response surface methodology. J Cent South Univ 25(02), 406-417 (2018)

10. Ministry of Construction of the People's Republic of China, Standard for Test Method of Performance on Ordinary Fresh Concrete (GB50080-2002) (China Building Industry Press, Beijing, 2003)

11. Ministry of Construction of the People's Republic of China, Standard for Test Method of Mechanical Properties on Ordinary Concrete (GB50081-2002) (China Building Industry Press, Beijing, 2003)

12. S.K. Rai, R. Konwarh, A.K. Mukherjee, Purification, characterization and biotechnological application of an alkaline $\beta$-keratinase produced by Bacillus subtilis RM-01 in solid-state fermentation using chicken-feather as substrate. Biochem. Eng. J. 45(3), 218-225 (2009) 
13. Y.B. Wang, Y.X. Wang, Optimization of cultivation conditions for extracellular polysaccharide fermented by Ustilago maydis using response surface methodology. China Brew 5, 56-60 (2006)

14. L. Wang, J.C. Li, J.F. Zhou, Numerical study of flocculation settling of cohesive sediment. Acta Phys Sin 59(05), 3315-3323 (2010)
Publisher's Note Springer Nature remains neutral with regard to jurisdictional claims in published maps and institutional affiliations. 